\title{
PERBEDAAN INDEKS PLAK PADA PENGGUNA ALAT ORTODONTIK CEKAT YANG MENGGUNAKAN SIKAT GIGI KHUSUS ORTODONTIK DENGAN DAN TANPA OBAT KUMUR
}

\author{
Windy Tjiali $^{1)}$, PS. Anindita ${ }^{1)}$, Olivia Waworuntu ${ }^{2)}$ \\ ${ }^{1)}$ Program Studi Pendidikan Dokter Gigi Fakultas Kedokteran UNSRAT Manado \\ ${ }^{2)}$ Program Studi Pendidikan Dokter Fakultas Kedokteran UNSRAT Manado \\ e-mail: tjialiwindy@gmail.com; ps_anindita@yahoo.com; waworuntu.olivia@gmail.com
}

\begin{abstract}
ABSTRAK
Perawatan ortodontik khususnya penggunaan alat ortodontik cekat memiliki bentuk yang rumit sehingga mempermudah melekatnya plak lebih lama dan dapat meningkatkan resiko karies, gingivitis, dan penyakit periodontal. Salah satu cara untuk mengurangi resiko yang ada adalah dengan melakukan kontrol plak. Kontrol plak dapat dilakukan secara mekanis (sikat gigi khusus ortodontik) dan kimiawi (obat kumur). Penelitian ini bertujuan untuk mengetahui perbedaan indeks plak pada pengguna alat ortodontik cekat yang menggunakan sikat gigi khusus ortodontik dengan tambahan obat kumur dan tanpa obat kumur. Jenis penelitian ini adalah eksperimen lapangan dengan rancangan the eqiuevalent material group, pretest and posttest design. Penelitian ini dilakukan dengan sampel mahasiswa angkatan 2011-2012 Program Studi Pendidikan Dokter Gigi Universitas Sam Ratulangi Manado sebanyak 33 orang. Pengambilan sampel dengan menggunakan metode purposive sampling. Data dianalisis menggunakan uji dependent t-test. Hasil analisis menunjukkan perbedaan penurunan indeks plak yang signifikan $(\mathrm{p}<0,05)$. Dapat disimpulkan bahwa terdapat perbedaan indeks plak pada pengguna alat ortodontik cekat yang menggunakan sikat gigi khusus ortodontik dengan tambahan obat kumur dan tanpa obat kumur.
\end{abstract}

Kata kunci : ortodontik cekat, sikat gigi khusus ortodontik, obat kumur, indeks plak.

\section{THE DIFFERENCE OF PLAQUE INDEX ON FIXED ORTHODONTIC USERS THAT USED ORTHODONTIC TOOTHBRUSH WITH AND WITHOUT MOUTHWASH}

\begin{abstract}
Orthodontic treatment especially fixed orthodontic appliance has a complex form that can simplify the attachement of plaque longer and could increase the risk of caries, gingivitis, and periodontal disease. One way to reduce the risk is plaque control. Plaque control can be done mechanically (orthodontic toothbrush) and chemically (mouthwash). This research aimed to know the difference plaque index on users of fixed orthodontic appliance that used orthodontic toothbrush with mouthwash and without mouthwash.This research is field experiments to a draf the eqiuevalent material group, pretest and posttest design. This research is done with a sample of 33 people of 2011-2012 dentist students of Sam Ratulangi University. The sample was collected by purposive sampling method. Data was analyzed by the dependent t-test. The result showed that there was significant decrease of plaque index $(p<0,05)$. In conclusion, there is a differenceplaque index on users of fixed orthodontic appliance that used orthodontic toothbrush with mouthwash and without mouthwash.
\end{abstract}

Key words: Fixed orthodontic, orthodontic toothbrush, mouthwash, plaque index.

\section{PENDAHULUAN}

Perawatan ortodontik khususnya penggunaan alat ortodontik cekat dengan komponen brackets, arch wires dan komponen lainnya memiliki bentuk yang rumit sehingga mempermudah melekatnya plak lebih lama dan dapat meningkatkan resiko karies, gingivitis, dan kemungkinan terjadi penyakit periodontal (Ay ZY, 2007) (Marinia I, 2014) (Chestnutt, 2007). Alat 
ortodontik cekat memiliki desain yang lebih sulit untuk dibersihkan dibandingkan dengan alat ortodontik lepasan, sehingga pasien pengguna alat ortodontik cekat lebih sulit untuk memelihara kebersihan mulut selama perawatan (Singh G, 2007).

Salah satu indikator untuk melihat kebersihan gigi dan mulut adalah plak gigi (Carranza FA, 2006). Plak dapat diartikan sebagai deposit lunak yang membentuk biofilm, melekat pada permukaan gigi atau permukaan kasar lain di dalam rongga mulut termasuk pada restorasi lepasan atau cekat.Pembersihan gigi yang kurang baik dapat menyebabkan plak semakin melekat (Reddy S, 2008) (Haake SK, 2011).

Kontrol plak dapat dilakukan secara mekanis dan kimiawi. Sikat gigi merupakan alat utama dalam melaksanakan kontrol plak secara mekanis (Iswari AP, 2010) (Sunnati, 2014). Pengguna alat ortodontik cekat dianjurkan untuk memakai sikat gigi desain khusus yaitu baris-baris tengah bulu sikat lebih pendek dibandingkan bulu sikat pada kedua pinggirnya untuk membantu pembersihan plak disekitar bracket (Syahra NA, 2014).

Kontrol plak secara kimiawi digunakan sebagai tambahan pada kontrol plak secara mekanis, salah satunya adalah obat kumur (Sunnati, 2014). Penggunaan obat kumur tidak dapat menggantikan kontrol plak secara mekanis seperti menyikat gigi. Obat kumur direkomendasikan untuk mengurangi pembentukan plak serta melindungi gusi dan gigi dari proses kerusakan (Forgas L, 2004).

Berdasarkan hal-hal tersebut, maka penulis tertarik untuk meneliti tentang perbedaan indeks plak pada pengguna alat ortodontik cekat yang menggunakan sikat gigi khusus ortodontik dengan dan tanpa obat kumur.

Tujuan dari penelitian ini untuk mengetahui perbedaan indeks plak pada pengguna alat ortodontik cekat yang menggunakan sikat gigi khusus ortodontik dengan tambahan obat kumur dan tanpa obat kumur.

\section{BAHAN DAN METODE}

Penelitian ini merupakan penelitian eksperimen lapangan dengan rancangan the equivalent material group, pretest-posttest design. Populasi dalam penelitian ini yaitu mahasiswa pengguna alat ortodontik cekat di Program Studi Pendidikan Dokter Gigi Fakultas Kedokteran Universitas Sam
Ratulangi Manado angkatan 2011 dan 2012. Sampel pada penelitian ini diambil secara purposive sampling. Besarnya sampel minimal yang digunakan dalam penelitian ini diperoleh dengan rumus Slovin dan didapatkan sampel berjumlah 33 orang.

Sampel yang berjumlah 33 orang ini, masing-masing menerima 2 perlakuan di hari yang berbeda. Perlakuan pertama yaitu menyikat gigi menggunakan sikat gigi khusus ortodontik tanpa obat kumur dan perlakuan ke-2 yaitu menyikat gigi menggunakan sikat gigi khusus ortodontik dengan tambahan obat kumur. Pemeriksaan indeks plak dilakukan sebelum dan setelah perlakuan dengan menggunakan larutan disclosing solution yang diaplikasikan pada permukaan gigi yang diperiksa. Pemeriksaan dilakukan pada 6 gigi yaitu gigi 16, 11, 26, 36, 31 dan 46, dengan permukaan gigi yang diperiksa untuk gigi incisivus dan gigi molar rahang atas yaitu sisi labial atau bukal dan untuk gigi molar rahang bawah yaitu sisi lingual. Permukaan gigi yang diperiksa dibagi menjadi 5 bagian (Gambar 1). Pada bagian yang terdapat plak diberi skor 1 dan pada bagian yang tidak terdapat plak diberi skor 0 .

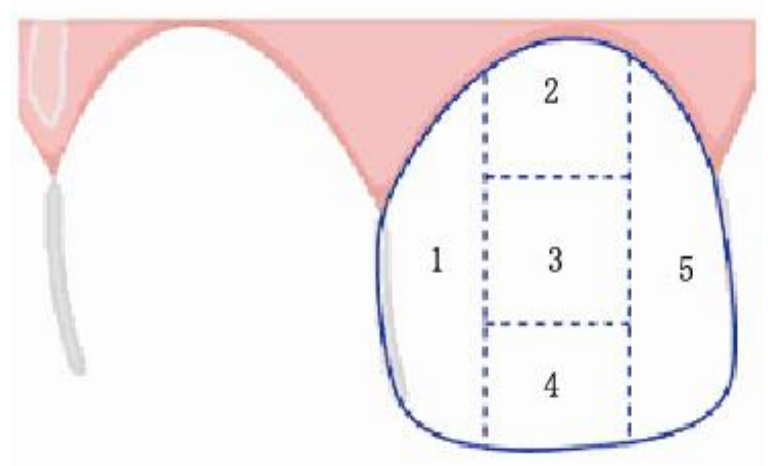

Gambar 1. Permukaan gigi dibagi menjadi 5 bagian (Marya CM, 2011)

Data yang diperoleh dimasukkan dalam tabel. Data kemudian dianalisis menggunakan uji statistik dependent t-test untuk mengetahui perbedaan penurunan indeks plak antara sikat gigi khusus ortodontik tanpa obat kumur dan sikat gigi khusus ortodontik dengan tambahan obat kumur. 


\section{HASIL PENELITIAN}

Hasil penelitian indeks plak pada pengguna alat ortodontik cekat yang menggunakan sikat gigi khusus ortodontik dengan dan tanpa obat kumur dapat dilihat pada Tabel 1-4.

Tabel 1. Distribusi responden berdasarkan jenis kelamin

\begin{tabular}{crc}
\hline Jenis Kelamin & $\mathrm{n}$ & $\%$ \\
\hline Laki-Laki & 8 & 24 \\
Perempuan & 25 & 76 \\
Total & 33 & 100 \\
\hline
\end{tabular}

Tabel 2. Distribusi responden berdasarkan usia

\begin{tabular}{crr}
\hline Usia (tahun) & $\mathrm{n}$ & $\%$ \\
\hline 19 & 1 & 3 \\
20 & 4 & 12 \\
21 & 16 & 49 \\
22 & 10 & 30 \\
23 & 1 & 3 \\
24 & 1 & 3 \\
Total & 33 & 100 \\
\hline
\end{tabular}

Tabel 3. Rerata indeks plak sebelum dan setelah menggunakan sikat gigi khusus ortodontik tanpa obat kumur dan dengan obat kumur

\begin{tabular}{ccccccc}
\hline \multirow{2}{*}{ Perlakuan } & \multirow{2}{*}{$\mathrm{n}$} & \multicolumn{2}{c}{ Sebelum } & \multicolumn{2}{c}{ Setelah } & \multirow{2}{*}{ Selisih Rerata } \\
\cline { 3 - 6 } Tanpa obat kumur & 33 & 3,555 & Buruk & 2,852 & Sedang & 0,703 \\
Dengan obat kumur & 33 & 3,621 & Buruk & 2,491 & Sedang & 1,130 \\
\hline
\end{tabular}

Tabel 4. Hasil uji dependent t-test penurunan indeks plak antara sikat gigi khusus ortodontik tanpa obat kumur dan dengan obat kumur

\begin{tabular}{ccccc}
\hline Perlakuan & $\mathrm{n}$ & Rerata & $\begin{array}{c}\text { Selisih } \\
\text { Rerata }\end{array}$ & Sig. \\
\hline Sikat gigi khusus ortodontik & 3 & 0,703 & & \\
& 3 & & 0,427 & 0,000 \\
Sikat gigi khusus ortodontik + obat kumur & 3 & 1,130 & & \\
\hline
\end{tabular}

\section{PEMBAHASAN}

Hasil analisis uji dependent T-test menunjukkan bahwa terdapat perbedaan penurunan plak yang bermakna antara penggunaan sikat gigi khusus ortodontik tanpa obat kumur dan penggunaan sikat gigi khusus ortodontik dengan tambahan obat kumur dengan nilai signifikansi 0,000 $(\mathrm{p}<0,05)$. Hasil ini serupa dengan hasil penelitian Hudiyoko pada tahun 2007 di Yogyakarta yang menunjukkan hasil bahwa terdapat penurunan plak yang bermaknaantara sikat gigi ortodontik manual dengan obat kumur dan sikat gigi ortodontik manual tanpa obat kumur (Hudiyoko K, 2007).

Hasil penelitian ini menunjukkan bahwa penggunaan obat kumur pada pengguna alat ortodontik cekat sebagai upaya tambahan setelah menyikat gigi perlu dilakukan karena menyikat gigi saja belum cukup untuk membersihkan plak secara menyeluruh (Tabel 4). Hal ini disebabkan oleh ketidakmampuan bulu sikat untuk menjangkau plak di daerah yang sulit dijangkau oleh sikat gigi seperti daerah interdental dan juga daerah tepi bracket pada pengguna alat ortodontik cekat (Singh G, 2007) (Darby ML, 2007). Obat kumur yang bentuk sediaannya cair mampu menjangkau plak yang terdapat di daerah yang sulit dijangkau oleh sikat gigi dan dengan mekanisme antimikrobialnya mampu membunuh bakteri dalam plak.

Obat kumur yang digunakan pada penelitian Hudiyoko berjenis 
Cetylpyridinium Chloride (CPC) sedangkan obat kumur yang digunakan dalam penelitian ini berjenis essensial oil. Kedua-duanya efektif dalam membantu mengurangi plak setelah menyikat gigi pada pengguna alat ortodontik cekat karena memiliki mekanisme antimikrobial.

Hasil analisis penelitian ini juga sejalan dengan penelitian Sharma et al dari Nepal tahun 2004 yang menunjukkan bahwa terdapat penurunan plak lebih banyak pada responden yang menambahkan obat kumur setelah menyikat gigi dibandingkan dengan responden yang hanya menyikat gigi saja (DePaola LG, 2007). Hasil ini menunjukkan bahwa obat kumur mampu membantu mengurangi plak setelah menyikat gigi baik pada pengguna alat ortodontik cekat maupun pada yang bukan pengguna alat ortodontik cekat.

Berdasarkan kategori rerata penurunan plak terlihat bahwa terdapat efek yang sama dalam mengurangi plak dari kategori buruk menjadi sedang antara penggunaan sikat gigi khusus ortodontik tanpa obat kumur dan penggunaan sikat gigi khusus ortodontik dengan tambahan obat kumur (Tabel 3). Hal ini disebabkan karena kontrol plak secara mekanik yaitu sikat gigi memiliki peran yang penting dalam membersihkan plak. Tekanan yang dihasilkan pada bulu sikat gigi secara langsung bergesekkan dengan permukaan gigi mampu mengurangi plak lebih banyak dibandingkan dengan obat kumur yang hanya mampu menjangkau permukaan gigi melalui aksi berkumur. Hasil penelitian ini sesuai dengan teori yang ada yaitu bahwa obat kumur hanya merupakan tambahan dari sikat gigi yang dapat membantu membersihkan plak namun tidak dapat menggantikan sikat gigi sebagai kontrol plak utama (Forgas L, 2004).

Obat kumur tetap dianjurkan untuk digunakan sebagai upaya tambahan kontrol plak setelah menyikat gigi karena penggunaan sikat gigi khusus ortodontik dengan tambahan obat kumur menunjukkan nilai indeks plak yang lebih baik dibandingkan dengan nilai indeks plak penggunaan sikat gigi khusus ortodontik tanpa obat kumur (Tabel 3). American Dental Association dalam The American Dental Association Council on Scientific menerbitkan anjuran penggunaan obat kumur antimikroba yang dapat membantu mencegah dan mengurangi plak sebagai upaya tambahan kontrol plak setelah menyikat gigi. Hal ini menjawab pertanyaan beberapa studi tentang solusi tambahan kontrol plak yang dapat membantu mengatasi masalah dari pasien-pasien yang tidak mampu membersihkan plak di daerah interdental dan daerah lainnya yang sulit dijangkau oleh sikat gigi (Darby ML, 2007) (DePaola LG, 2007).

\section{SIMPULAN}

Terdapat perbedaan indeks plak yang bermakna dengan nilai signifikansi $(p<0,05)$ pada pengguna alat ortodontik cekat yang menggunakan sikat gigi khusus ortodontik dengan tambahan obat kumur dan tanpa obat kumur.

\section{SARAN}

Perlunya penggunaan obat kumur sebagai upaya tambahan kontrol plak setelah menyikat gigi pada pengguna alat ortodontik cekat. Diharapkan pula dapat dilakukan penelitian lebih lanjut tentang penggunaan obat kumur terhadap penyakit-penyakit yang disebabkan oleh akumulasi plak seperti gingivitis, penyakit periodontal dan karies.

\section{DAFTAR PUSTAKA}

Ay ZY, Sayin MO, Ozat Y, Goster T, Atilla AO, Bozkurt FY. 2007. "Appropriate oral hygiene motivation method for patients with fixed appliances" [online]. Angle Orthodontist 77(6). availablefrom:http://www.angle.org/do i/abs/10.2319/101806-428.1 (diakses 20 Maret 2015).

Carranza FA, Newman MG. 2006.Clinical periodontology. 9th Ed. Philadelphia: W.B. Saunders; p.76.

Chestnutt IG, Gibson J. 2007.Clinical dentistry. $3^{\text {rd }}$ ed. Philadelphia: Elsevier; p.345.

Darby ML. 2007."Changing perspectives on the use of antimicrobial mouthrinses". Journal of Dental Hygiene: 3.

DePaola LG, Spolarich AE. 2007. "Safety and efficacy of antimicrobial mouthrinses in clinical practice". Journal of Dental Hygiene: 13-25. 
Forgas L. 2004. Pengendalian plak. In: Fedi PF, Vernino AR, Gray JL,editors. Silabus periodonti. Edisi 4. Jakarta: EGC;hal.73, 81-2.

Haake SK. 2011. Etiology of periodontal diseases. In: Newman MG, Takei HH, Carranza FA,editor. Carranza's clinical periodontology. $11^{\text {th }}$ ed. St Louis: Saunders Elsevier;p.95-98.

Hudiyoko K, Soehardono. 2007. Perbandingan efektivitas sikat gigi ortodontik manual dan elektrik dengan dan tanpa obat kumur antiseptik Cetylpyridinium Chloride terhadap penurunan plak pada pemakai alat ortodontik cekat: Kajian teknik Begg tahap pertama[online]. availablefrom:http://etd.repository.ugm .ac.id/index.php?mod=penelitian_detai $1 \&$ sub=PenelitianDetail\&act=view\&ty $\mathrm{p}=\mathrm{html} \&$ buku_id $=33682$ (diakses 5 Mei 2015).

Iswari AP, Riyanti E, Hadidjah D. 2010."Plaque index differences before and after teeth brushing with and without propolis dentifrice". Padjadjaran J Dent Maret 22(1): 3742.

Marinia I, Bortolottib F, Parentic SI, Gattod MR, Bonettid GA. 2014."Combined effects of repeated oral hygiene motivation and type of toothbrush on orthodontic patients"[online]. Angle Orthodontist. 84(5)available from: http://www.angle.org/doi/pdf/10.2319/ 101806-428.1 (diakses 5 Mei 2015).

Marya CM. 2011.Dental Indices. In : Marya $\mathrm{CM}$, editor. A textbook of public health dentistry. $1^{\text {st }}$ ed. New Delhi: Jaypee Publishers; p.192-93, 204-05.

Reddy S. 2008. Essentials of clinical periodontology and periodontics. $2^{\text {nd }}$ ed. New Delhi: Jaypee; p.57,59,61-2.

Singh G. 2007.Fixed orthodontic appliances. In: Singh G,editors. Text Book of Orthodontics. $2^{\text {nd }}$ ed. New Delhi: Jaypee Publishers; p.449.

Sunnati. 2014. "Efektifitas berkumur dengan obat kumur kombinasi minyak esensial dan teh hijau". Cakradonya Dent $J$ 6(1): 667-71.
Syahra NA. 2014.Perbandingan ortodontik plak indeks pada pasien pemakai fixed orthodontic sebelum dan sesudah tooth brush instruction. Makasar: Universitas Hassanudin; Skripsi. 